\title{
A Study to Assess the Knowledge and Attitude on No-Scalpel Vasectomy Among Teachers at Selected Schools
}

\author{
*Subakeerthi.V
}

\begin{abstract}
:
Objectives: To assess the level of knowledge and attitude regarding No-Scalpel Vasectomy among Teachers. Methods: Descriptive research design was used for the study Results: It shows that out of 100 samples2\% of teachers had Adequate Knowledge, 21\% of teachers had Moderate Adequate Knowledge and 77\% majority of teachers had Inadequate Knowledge and it showed that 8\% of teachers had Most Favorable Attitude, 50\% of teachers had Favorable Attitude and $42 \%$ of teachers had unfavorable Attitude on No-Scalpel Vasectomy. Conclusion: The finding of the study revealed that majority of the teachers had inadequate knowledge regarding No-Scalpel Vasectomy. Community health nurse should be aware of need for educating on No-scalpel vasectomy among school teachers, this will help to provide adequate information to urban and rural people.
\end{abstract}

Key words: No-Scalpel Vasectomy, teachers.

\section{INTRODUCTION:}

India is the second largest country as per the world population. In the last decade the population of India increased by 181 million ${ }^{1}$. There is a need to educate them by appropriate technology to have a control over population growth. Survey from more than 60 developing countries indicates that more than 100 million people are currently not using contraceptive method and want to delay the birth of their child or to stop having children. 350 million couples do not have access to a choice of safe and affordable contraceptive method ${ }^{2}$
The family planning programmers have always focused on women instead of men since yesteryears. The family planning has become a domain of women and one finds more women opting for permanent family planning methods than men. The introduction of No-Scalpel Vasectomy (NSV) technique which does not involve ascalpel has helped to increase the acceptability of sterilization among men, as it is safe, simple, quick and has negligent complications than the traditional vasectomy ${ }^{3}$ 


\section{OBJECTIVES}

1. To assess the level of knowledge and attitude regarding No-Scalpel Vasectomy among Teachers.

2. To correlate the knowledge and attitude of Teacher regarding no scalpel vasectomy.

3. To associate the level of knowledge and attitude regarding No-Scalpel Vasectomy with selected demographic variable

\section{METHODOLOGY}

Research approach of this study is quantitative approach. .The research design used for this study was Descriptive research design. The study was conducted in selected Higher Secondary Schools in Chennai with 100 Married Male Teachers who have completed their education, training, qualification and were selected by using non-probability convenient sampling technique. The data were analyzed by using descriptive statistics like frequency, percentage, mean, standard deviation.

\section{MAJOR FINDINGS}

\section{Distribution of Level of Knowledge} on No-Scalpel Vasectomy among Teachers

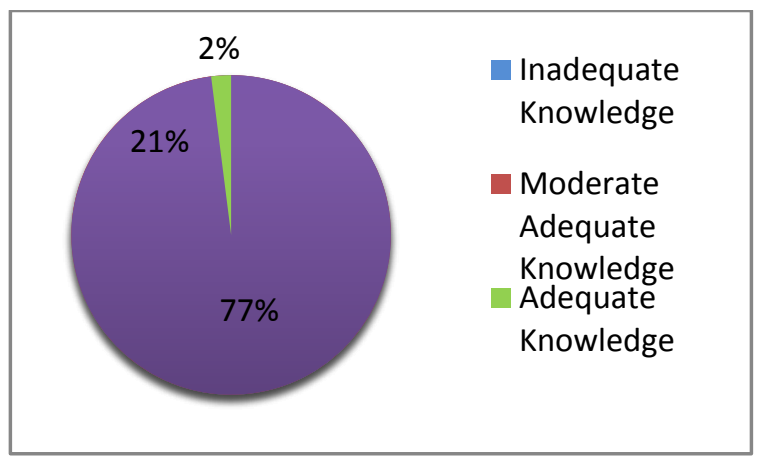

The above figure shows that $2 \%$ of them had Adequate Knowledge on NoScalpel Vasectomy, 21\% of them had Moderate Adequate Knowledge on NoScalpel Vasectomy and $77 \%$ majority of them had Inadequate Knowledge on NoScalpel Vasectomy.

\section{Distribution of Level of Attitude on No-Scalpel Vasectomy among Teachers}

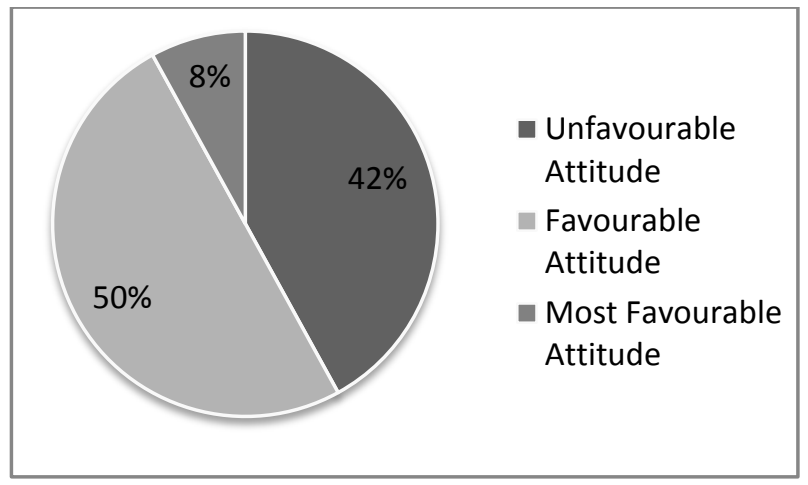

The above figure shows that $8 \%$ of them had Most Favorable Attitude on NoScalpel Vasectomy, 50\% of them had Favorable Attitude on No-Scalpel Vasectomy and $42 \%$ of them had Unfavorable Attitude on No-Scalpel Vasectomy

\section{RESULTS:}

The demographic characteristics revealed that most of the participants were in the age group of 31-40 years, (55\%) 55 in joint family, (63\%) 63 belonged to Hindu religion, (83\%) 83 were educated up to post graduation, $(68 \%) 68 \mathrm{had}$ monthly income more than Rs. 15,000 (55\%) 55 of them had two children, (83\%) 83 of family members/ relatives had not adopted vasectomy, (56\%) 56 of them not heard of No-Scalpel Vasectomy and (52\%) 52 of them not adopted any method of family planning. 
It was also noted that overall knowledge mean score was 39.20 with standard deviation 15.02. (21\%) 21 had moderately adequate knowledge, (77\%) 77 had inadequate knowledge. It was also noted that overall mean score of attitude was 55.55 with standard deviation 13.48 and (50\%) 50 of them had favorable attitude (42\%) 42 had unfavorable attitude on No-Scalpel Vasectomy among teachers. It revealed that positive correlation existed between knowledge and attitude on No-Scalpel Vasectomy among teachers. The correlation was found statistically significant at $\mathrm{P}<0.05$. It was also noted that there was a significant association between levels of knowledge with religion at $\mathrm{p}<0.05$, $\mathrm{p}<0.01$ level.

There was no significant association between level of knowledge with Age, Type of family, Education status, Training, Family/friends adopted vasectomy outcome, Heard of No-Scalpel Vasectomy about sources and Adopted method of family planning at $\mathrm{p}>0.05$. It was also noted that there was significant association between attitude with Age, Monthly Income, Heard of No Scalpel Vasectomy at $\mathrm{p}<0.05, \mathrm{p}<0.01$ level. There was no significant association of Attitude with, Type of family, Education status, Training, Family/friends adopted vasectomy outcome, and Adopted method of family planning $\mathrm{p}>0.05$.

\section{LIMITATION}

- The study was limited to Teachers with minimum of U.G qualification.

- The study was limited to 6 weeks

\section{CONCLUSION:}

Community health nurse should be aware of need for educating on No-scalpel vasectomy among school teachers; this will help to provide adequate information to urban and rural people.

\section{REFERENCES:}

1. Department of family welfare (2003) "National population policy" ministry of health and family welfare, government of India page no: 12-15.Family planning and population division of family health world health organisation (1994) vasectomy what health workers need to know WHO/ FHE/ 93.4 rev 1 page no: 1-31

2. Govt of India (2001), No-Scalpel Vasectomy father is equally responsible for the happiness of the family, department of family welfare, page no $12,18$.

3. Basavanthappa B.T. (2007) "Community health nursing”, Bangalore, Jaypee Brothers Publication, New Delhi, India.

4. Bhusan and Sachdeva D.R (1994), "Rural and urban community, A introduction to sociology 1 stEdition, kitabmhal Allahabad, page no: 519-553.

5. Dulta D.G. (1995) "Text book of obstetrics" 1stEdition,Central publishers, Calcutta page no: 562-564.

6. Family planning and population division of family health world health organisation (1994) vasectomy what health workers need to know WHO/ FHE/ 93.4 rev 1 page no:1-31. 